\title{
O Jardim Proibido: o Peso de Vender Pastel no Lugar Errado
}

\section{The Forbidden Garden: the Weight of Selling Pastries in the Wrong Place}

\author{
José Ednilson Matos Júnior \\ Universidade Federal de Sergipe - UFS - Brasil \\ jrmatosrh@gmail.com \\ ORCID: 0000-0001-9232-2100 \\ Marcio Roque dos Santos da Silva \\ Universidade Federal de Sergipe - UFS - Brasil \\ santosmarcioadm@gmail.com \\ ORCID: 0000-0001-7194-9094 \\ Maria Elena Leon Olave \\ Universidade Federal de Sergipe - UFS - Brasil \\ mleonolave@academico.ufs.br \\ ORCID: 0000-0002-7367-4896 \\ Felipe Borges de Santana \\ Universidade Federal de Sergipe - UFS - Brasil \\ feelip-borges@hotmail.com \\ ORCID: 0000-0002-1817-1030
}

Submetido em 07/10/2020; Aprovado em 07/11/2020.

\begin{abstract}
Resumo
Contexto: Este caso para ensino conta a trajetória de sucesso de um casal de empreendedores do ramo alimentício da cidade de Aracaju/Sergipe, permeando os desafios e as conquistas enfrentados nessa jornada. Trata-se de uma história real, contudo os diálogos foram simulados para ilustrar a sequência dos fatos. A análise se concentra na fase de expansão do negócio e suas consequências, evidenciando abordagens que permitem refletir a relevância de ferramentas gerenciais, como o Plano de Negócios; do planejamento estratégico; e da tomada de decisão gerencial a partir do diagnóstico organizacional e ambiental. Objetivos de ensino: Espera-se que os alunos compreendam a importância do diagnóstico empresarial e ambiental, auxiliado por ferramentas de gestão, para a tomada de decisão, considerando ações estratégicas para solucionar problemas diagnosticados. Fontes de dados: Os dados foram produzidos por meio de entrevista semiestruturada, com o casal de empreendedores, e de fontes secundárias. Aplicação: 0 conteúdo é sugerido para cursos de graduação e pós-graduação em Administração, Gestão de Negócios, Gestão Empresarial e áreas afins, em disciplinas como: Empreendedorismo; Gestão de Negócios; Planejamento Estratégico; e, Análise Financeira.
\end{abstract}

Palavras-chave: Empreendedorismo. Gestão de Negócios. Planejamento Estratégico. Caso para Ensino.

\section{Abstract}

Context: This teaching case tells the success story of a couple of entrepreneurs in the food industry in the city of Aracaju/Sergipe, permeating the challenges and achievements faced in this journey. It is a real story, however the dialogues were simulated to illustrate the sequence of events. The analysis focuses on the business expansion phase and its consequences, showing approaches that allow reflecting the relevance: of management tools, such as the Business Plan; strategic planning; and managerial decision making based on the organizational and environmental diagnosis. Teaching objectives: Students are expected to understand the importance of business and environmental diagnosis, aided by management tools, for decision making, considering strategic actions to solve diagnosed problems. Data sources: The data were produced through semi-structured interviews, with the couple of entrepreneurs, and from secondary sources. Application: The content is suggested for undergraduate and grad- 
uate courses in Administration, Business Management, Business Management and related areas, in disciplines such as: Entrepreneurship; Business management; Strategic planning; and Financial Analysis. Keywords: Entrepreneurship. Business management. Strategic planning. Teaching Case.

\section{Introdução}

Olá! Você conhecerá a história de um casal de empreendedores do ramo alimentício, que atua no mercado sergipano há quase duas décadas. 0 texto conta a trajetória de sucesso, conquistas e desafios enfrentados na jornada empreendedora do casal Silva, concentrando sua análise no processo de expansão do negócio que consistiu na construção de uma loja em um shopping do interior do estado e as consequências dessa decisão.

Este exemplo propõe uma reflexão sobre a relevância do cumprimento das etapas que compõem o plano de negócios, as quais são necessárias para a abertura e/ou expansão de empresas; do planejamento alinhado às necessidades organizacionais e ambientais; e da tomada de decisão gerencial, com base em informações consistentes e análise financeira.

A história desse casal, que começou com uma barraquinha de pastel na orla da cidade de Aracaju/SE e, atualmente, é um empreendimento de sucesso em processo de expansão, revela uma trama que é comum a grande parte dos micro e pequenos empreendedores brasileiros, os quais na busca pela sobrevivência e pelo alcance de seus sonhos e objetivos, enfrentam desafios e dilemas de forma contínua.

Aqui, o leitor é convidado a conhecer os dramas vividos pelo casal Silva e a assumir o posto de "dono do negócio", sendo responsável pela tomada de decisões diante dos dilemas propostos. O que você faria de diferente do casal Silva? Onde eles falharam? Onde acertaram? Quais são as soluções que você apresenta para este caso? Essas e outras indagações você poderá solucionar à medida que for experienciando o desenrolar da história vivida pelos empreendedores. Boa leitura!

\section{Entendendo o caso}

Nesta seção, você conhecerá a trajetória vivenciada pelos Silva. Para sua melhor compreensão, ressalta-se que a narrativa utiliza elementos bíblicos no início de cada tópico para traçar um paralelo entre a história de Adão e Eva e a situação experienciada por Maria e João Silva.

\subsection{Eva e Adão no Jardim do Éden: o princípio}

Assim como o Jardim do Éden foi construído do caos, foi também o início da vida empreendedora do casal Maria Silva e João Silva que, diante das dificuldades econômicas enfrentadas, decidiram deixar seus empregos formais, na área do turismo, para construírem o seu "jardim". 0 casal decidiu abrir uma barraquinha de pastel numa feirinha gastronômica localizada na orla da cidade de Aracaju, local privilegiado e estratégico, em meados de 2008. A princípio, eles contaram com as redes de contatos que tinham criado ao longo das suas trajetórias profissionais e pessoais e, aos poucos, o negócio foi crescendo, as demandas foram aumentando e, por consequência, a lucratividade, chegando a um faturamento mensal de cerca de $\mathrm{R} \$ 80.000,00$ reais. 0 sucesso da barraquinha de pastel levou Maria a sonhar com a abertura de uma loja física que permitisse ampliar o número de atendimentos, melhorar a qualidade do produto e oferecer mais conforto e comodidade para sua clientela.

Em 2012, com seu "jardim" pronto, a tarefa agora era cuidar do negócio e trabalhar para a consolidação dele - o que aconteceu. 0 negócio deu tão certo que virou até reportagem no programa de TV Aberta intitulado "Pequenas Empresas e Grandes Negócios" (Figura 1), o que atraiu pessoas de diversos lugares do país para conhecerem de perto sua história e experienciarem o ambiente promovido pelo empreendimento. Eles passaram a ser convidados para palestrarem para empreendedores, estudantes, profissionais da área de gestão e afins. Maria se tornou uma das grandes referências de Mulher Empreendedora do Estado, ganhando prêmios de reconhecimento dos serviços prestados à sociedade e representando o estado de Sergipe em encontros regionais e nacionais de Micro e Pequenos Empreendedores (SEBRAE, 2017).

Enquanto o negócio crescia cada vez mais, em 2015, o casal sentiu a necessidade de reformar a loja e expandir o espaço para melhor atender sua clientela. Para isso, venderam até a casa própria e investiram todo o dinheiro, confiando que com o retorno do investimento iriam poder comprar, mais tarde, uma casa maior e melhor. 


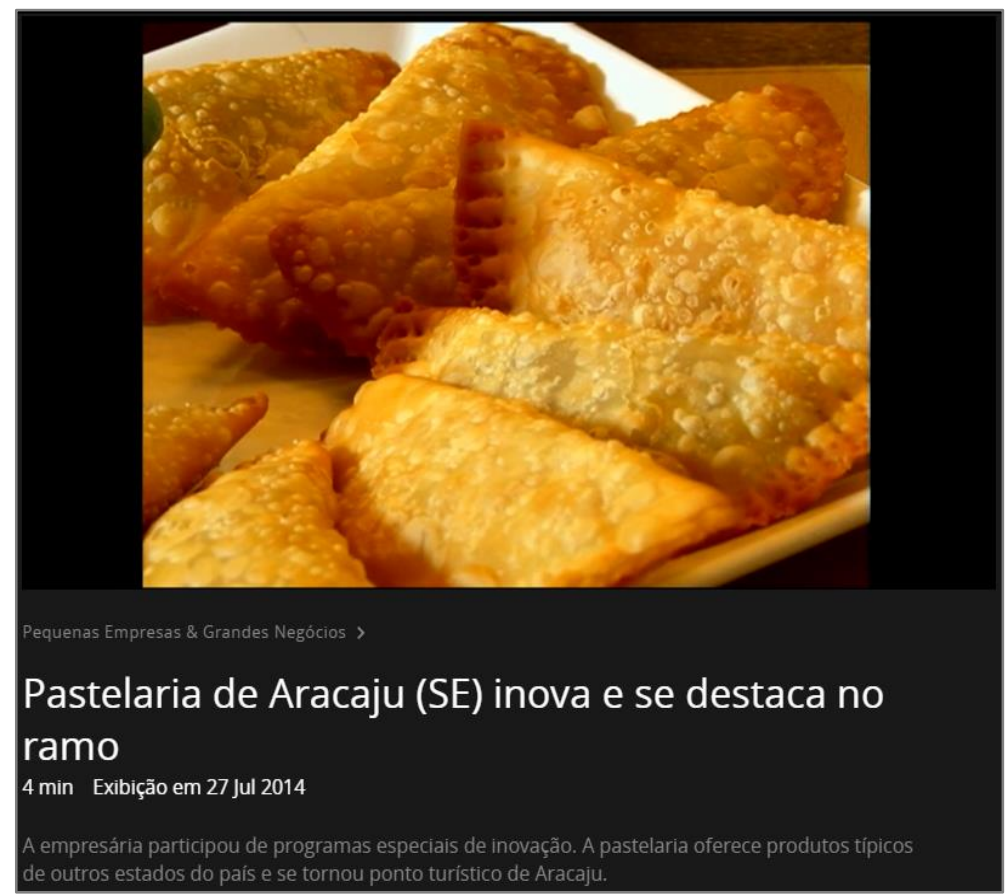

Figura 1: Reportagem no programa de TV Aberta Fonte: https://globoplay.globo.com/v/3520197/.

\subsection{Eva e a serpente: a proposta}

Eva passeava pelo jardim, contemplando toda a beleza das flores e dos frutos, admirando a tranquilidade dos animais, refrescando-se às margens do rio cristalino, e se deparou com a serpente que, de imediato, começou a conversar com ela, lançando todo o seu encanto para atraí-la.

Similar ao ocorrido com Eva, certo dia Maria descansava em sua casa, feliz por mais uma conquista, a reforma da sua loja, e pensava em sua trajetória vitoriosa, quando seu telefone tocou. Era a representante de um grande empreendimento comercial que estava em fase de lançamento no interior do estado. Ela gostaria de oferecer uma oportunidade para a expansão da pastelaria de Maria. A proposta era a abertura de uma filial em um shopping de uma cidade reconhecida pela força do comércio local. A representante enfatizou os benefícios que surgiriam com a abertura do negócio, mas Maria não ficou convencida da proposta e informou que não possuía interesse.

Alguns dias depois, o próprio dono do empreendimento - Sr. Linhares - entrou em contato com Maria e João, convidando-os para uma reunião a fim de apresentá-los o empreendimento de perto, acreditando que, assim, convenceria o casal Silva a aceitar a proposta. No início, Maria apresentou resistência, porém João a convenceu de que não seria uma má ideia ir até o local para conhecer a estrutura do empreendimento.

No dia e hora marcados, o casal foi até o local, sendo recepcionado pela representante do negócio (a serpente do jardim - aquela da primeira ligação):

- Bom dia, senhores! É uma satisfação tê-los aqui e será uma satisfação ainda maior contar com vocês nesse nosso novo empreendimento de sucesso! - Falou com entusiasmo a representante que os recebeu. - Agradecemos a receptividade! - respondeu Maria.

- O Sr. Linhares não pôde estar aqui, pois precisou viajar a negócios, mas me pediu para que eu os recebesse. Como vocês podem ver, nosso empreendimento é um grande negócio que impactará o comércio dessa cidade e de toda a região.

- Grande mesmo! - João exclamou entusiasmado, enquanto Maria assustada observava tudo a sua volta (as máquinas trabalhando, as estruturas sendo montadas, o grande volume de material de construção). - Então, Sr. João e Sr. ${ }^{a}$ Maria, temos uma proposta irresistível para vocês! Sabemos do potencial empreendedor que possuem e da história de sucesso de vocês e queremos contribuir ainda mais para a prosperidade de vocês. - anunciou a representante, que continuou:

- Aproveitando a força do comércio da região e considerando a recuperação, ainda que tímida, da economia do país, as previsões de rentabilidade do negócio são crescentes e bastante interessantes. Além disso, nossa proposta é que vocês não tenham que pagar nada pelo espaço, apenas ficariam responsáveis pelo 
custo da construção estrutural da loja de vocês.

- Olha que legal! - João reagiu de forma positiva à proposta. Maria seguiu observando em silêncio.

- Isso mesmo, Sr. João! Bastante interessante! Não tenho dúvidas de que esse é um negócio viável e que vocês, com a expertise e toda experiência empreendedora que possuem, farão desse empreendimento um negócio de sucesso, contribuindo também para o sucesso do nosso estabelecimento. - Falou a representante, que valendo-se da empolgação de João, reforçou a proposta.

- Ok! Agradecemos a atenção! Vamos analisar com calma e entraremos em contato. - Maria finalizou a conversa.

Voltaram para casa e Maria continuava achando que aquela proposta não seria interessante para o momento atual da pastelaria. 0 casal tinha acabado de concluir a expansão da loja principal e tinha investido muito nessa reforma, inclusive tinha vendido a própria casa para realizar o investimento. $\mathrm{Ou}$ seja, não tinha capital para uma nova aplicação naquele momento.

\subsection{0 fruto proibido é comido: a aceitação}

Alguns dias depois da visita, o casal recebeu outra vez a ligação do dono do empreendimento, convidando-os para uma reunião com os investidores e empreendedores do shopping. Na ocasião, Maria avisou que não poderia ir porque já tinha um compromisso e João foi à reunião, como representante do casal.

De modo diferente ao que aconteceu no Jardim do Éden, quem comeu do fruto proibido nessa história foi o homem, João, que encantado com as promessas fechou o contrato ali mesmo, voltando para casa com a novidade:

- Querida! A reunião foi excelente! Estou convencido de que esse é um bom negócio e, portanto, já fechei contrato com eles - disse ele entusiasmado.

Assustada, Maria respondeu:

- Como assim, João? Que história é essa de já ter fechado o contrato?! Você nem falou comigo...

- Querida, a proposta que eles apresentaram na reunião é muito boa! - João justificou sua decisão.

- João, não fizemos um plano de negócios... não fizemos um estudo de viabilidade... não dá para saber se esse negócio é um bom negócio. Essa decisão foi muito precipitada! - disse Maria.

- Maria, meu amor, não estamos fazendo negócio com qualquer um. Esses empreendedores estão no mercado há muito tempo e possuem experiências de sucesso no estado e, principalmente, na região em que atuam. Eles não entrariam em um negócio se não fosse promissor! E para um empreendimento desse porte, todos esses estudos e análises de investimento já devem ter sido realizados. Vamos acreditar nas promessas que foram feitas! - João argumentou.

Pensativa, Maria respirou fundo e foi para o seu quarto. Contrato fechado, o que restava para ela era unir forças ao marido e encarar mais esse desafio.

\subsection{0 conhecimento do bem e do mal: as consequências}

Assim como a decisão de comer o fruto modificou a realidade de vida do casal no Jardim do Éden, o mesmo aconteceu com o casal empreendedor ao tomar a decisão de abrir a loja no shopping do interior. Em 2016, logo após ter concluído a reforma da loja na capital, começaram a construção do novo empreendimento, porém não demorou muito e o dinheiro reservado acabou. Com a falta de capital, outros problemas foram surgindo e provocando uma série de consequências drásticas para a vitalidade do negócio.

- Maria, estava refletindo... temos nosso negócio na capital que, graças a Deus, está dando certo. Penso que, nesse início, podemos tirar dinheiro da matriz e investir na construção da filial, depois devolvemos. - disse João.

Maria respirou fundo...

- Além disso, pensei que poderíamos alugar um apartamento simples no interior para facilitar a logística... aí dividimos nosso tempo entre a capital e o interior, de modo que possamos dar assistência às duas lojas.

- continuou João. 
Reflexiva, Maria respondeu:

- Quanto ao aluguel do apartamento talvez seja uma boa ideia, acho que precisamos de um local, de fato, para melhor acompanharmos o andamento da construção e até para facilitar a compra e transporte dos materiais necessários.

- Isso mesmo! - João concordou.

- Vamos ter que sangrar a loja da capital para construir a loja do interior. Isso me deixa muito preocupada! Já estamos prejudicando a loja central demais! Estamos tendo alguns problemas com nossos funcionários que não tínhamos antes. Alguns clientes reclamando da qualidade do atendimento e dos serviços e isso me deixa muito preocupada! Tenho medo de que essa decisão precipitada nos cause sérios danos. - Maria afirmou e, em seguida, silenciou.

Com esforço e grande acúmulo de dívidas, a loja ficou pronta, mas o shopping não. 0 shopping, que também estava em construção, começou a atrasar os prazos que tinham sido estipulados no contrato. E agora, Maria e João, que tinham retirado capital de um empreendimento para investir em outro, se viram de mãos atadas, pois com o empreendimento fechado não teriam como iniciar suas atividades comerciais e obter o retorno do investimento que esperavam para cumprir com as obrigações assumidas na construção da nova empresa.

Após um ano de atraso, o shopping foi inaugurado. Como se não bastasse a demora para o início do funcionamento do shopping e as complicações financeiras advindas desse atraso, contrariando todas as expectativas apresentadas pelo grupo empreendedor, a adesão por parte da comunidade local foi aquém do esperado. No primeiro mês de lançamento, a demanda estava dentro do esperado, porém, a partir do segundo mês, a frequência de consumidores e até mesmo visitantes no shopping diminuiu de forma significativa, impactando diretamente nas vendas da pastelaria, que chegou a faturar em média $\mathrm{R} \$ 90,00$ reais por dia.

À certa altura, Maria indagou:

- Como manter um negócio com um quadro de 7 funcionários e os demais custos operacionais com um faturamento em torno de $R \$ 90,00$ reais ao dia?!

Esse era um questionamento que pairava os pensamentos do casal de empreendedores. Depois de todo o esforço realizado para construir a loja, eles estavam vendo o negócio indo de mal a pior.

E agora? 0 que fazer?

\subsection{Fechar ou revitalizar o jardim: será o fim?}

Era carnaval e para atrair clientes para a loja, em uma tentativa quase desesperada, Maria preparou mini pastéis e foi para o shopping fazer uma ação comercial. A ideia era proporcionar aos clientes uma experiência de degustação, apresentando a qualidade do produto, porém, ao chegar no estabelecimento, deparou-se com um ambiente quase desértico.

Desmotivada e séria, pensou: "Qual será o futuro do meu negócio? Como eu conseguirei pagar as dívidas geradas com aquele investimento?"

Encerrado aquele dia de trabalho, arrumou as coisas e voltou para casa, buscando encontrar uma resposta para seus questionamentos. Chegando em casa, encontrou João cabisbaixo refletindo sobre a realidade vivenciada em seus negócios. João disse:

- Querida, você não saiu daqui dizendo que só voltaria amanhã? - recebeu sua esposa assustado com o retorno precoce.

- Naquela cidade, eu não fico mais nenhum dia, João! - respondeu Maria emocionada.

- Calma, querida! Não está fácil, mas precisamos manter a calma. Não é a primeira dificuldade que enfrentamos na nossa trajetória. - disse João, tentando acalmá-la.

- Querido, esse negócio está afetando cada vez mais nossa saúde, nossa família e o nosso empreendimento principal, que é a loja da orla! Precisamos entender que quanto mais tempo insistirmos, maiores serão as dívidas e os desgastes físicos, emocionais, financeiros e legais. - argumentou Maria.

O silêncio pairou no ar por alguns segundos, então João disse:

- E se for só uma fase? Se for só o tempo de adaptação?

- E você pretende esperar até quando, João?! Enquanto esperamos, vamos fazer o quê? Quais são as estratégias que podemos utilizar para mudar? - interpelou Maria em tom já de desespero. 
O silêncio envolveu o quarto do casal e eles emudeceram. No dia seguinte, João se levantou bem cedinho, um pouco mais aliviado e encontrou sua esposa na cozinha fazendo o café da manhã:

- Bom dia, querida! Dormiu bem?

- Bom dia, João! Um pouco e você?

- Maria, estava refletindo sobre nossa conversa de ontem à noite e pensei em pedir ao Pedro um levantamento financeiro para sabermos nossa real situação e, a partir daí, tomarmos uma decisão mais sólida.

- Excelente! Apesar de temer o resultado, acho que é o melhor a se fazer agora!

Maria concordou e juntos se sentaram para o café da manhã.

Pedro Cardoso é um profissional experiente, contador de renome na região em que atua, e assessora o casal Silva na gestão financeira e contábil de seu empreendimento. Ao receber a solicitação do casal, de imediato Pedro enviou as planilhas e documentos solicitados.

Maria, analisando a primeira planilha, disse:

- João, estou assustada com nosso prejuízo! Sabia que não estávamos bem, mas está muito além daquilo que imaginava, olhe isso! - apontou para a primeira planilha que continha a Demonstração do Resultado do Exercício (DRE) (Tabela 1).

\begin{tabular}{lrr}
\hline \multicolumn{3}{c}{ DRE DA EMPRESA SILVA - SHOPPING (07/2017 a 03/2018) } \\
\hline RECEITAS & $\mathbf{R} \$$ & $\mathbf{3 7 . 8 0 0 , 0 0}$ \\
(-) CUSTOS & $-\mathrm{R} \$$ & $13.230,00$ \\
(=) LUCRO BRUTO & $\mathbf{R} \$$ & $\mathbf{2 4 . 5 7 0 , 0 0}$ \\
(-) DESPESAS & $-\mathrm{R} \$$ & $649.570,00$ \\
(-) Despesas com estrutura & $-\mathrm{R} \$$ & $362.480,00$ \\
(-) Despesas com funcionários & $-\mathrm{R} \$$ & $65.590,00$ \\
(-) Despesas com equipamentos & $-\mathrm{R} \$$ & $215.000,00$ \\
(-) Despesas com aluguel do apartamento & $-\mathrm{R} \$$ & $2.100,00$ \\
$\quad$ (-) Despesas com água e energia elétrica & $-\mathrm{R} \$$ & $4.400,00$ \\
(=) PREJUÍzO ACUMULADO (LUCRO LíQUIDO) = & $-\mathbf{R} \$$ & $\mathbf{6 2 5 . 0 0 0 , 0 0}$ \\
\hline
\end{tabular}

Tabela 1: DRE da filial da empresa aberta no shopping.

Fonte: Adaptado Dados da Pesquisa (2019).

João contra-argumentou:

- No começo é assim mesmo, Maria. Lembra como foi na nossa primeira loja?

Maria ressaltou:

- João, veja o prejuízo acumulado! - disse ela assustada e continuou - ainda tem o Balanço Patrimonial e mostrou a segunda planilha (Tabela 2).

\begin{tabular}{|c|c|c|c|c|c|}
\hline \multicolumn{6}{|c|}{ BALANÇO PATRIMONIAL DA EMPRESA SILVA - SHOPPING (03/2018) } \\
\hline \multicolumn{3}{|c|}{ ATIVO } & \multicolumn{3}{|c|}{ PASSIVO } \\
\hline ATIVO CIRCULANTE & $-\mathbf{R} \$$ & $48.500,00$ & PASSIVO CIRCULANTE & $\mathbf{R} \mathbf{S}$ & $185.844,00$ \\
\hline Caixa & $\mathrm{R} \$$ & & Empréstimos & $\mathrm{R} \$$ & $169.504,00$ \\
\hline Bancos & $-\mathrm{R} \$$ & $49.730,00$ & Salários & $\mathrm{R} \$$ & $7.496,00$ \\
\hline \multirow{3}{*}{ Estoque } & $\mathrm{R} \$$ & $1.230,00$ & Água e energia elétrica & $\mathrm{R} \$$ & 624,00 \\
\hline & & & Fornecedores & $\mathrm{R} \$$ & $6.530,00$ \\
\hline & & & Tributos & $\mathrm{R} \$$ & $1.690,00$ \\
\hline ATIVO NÃO CIRCULANTE & $\mathbf{R} \mathbf{S}$ & $199.520,00$ & PASSIVO NÃO CIRCULANTE & $\mathbf{R} \mathbf{S}$ & $370.176,00$ \\
\hline Móveis e utensílios & $\mathrm{R} \$$ & $41.760,00$ & Empréstimos & $\mathrm{R} \$$ & $370.176,00$ \\
\hline (-) Depreciação & $-\mathrm{R} \$$ & $3.240,00$ & PATRIMONIO LÍQUIDO & $-\mathbf{R} \$$ & $405.000,00$ \\
\hline Máquinas e equipamentos & $\mathrm{R} \$$ & $157.760,00$ & Capital social & $\mathrm{R} \$$ & $220.000,00$ \\
\hline (-) Depreciação & $-\mathrm{R} \$$ & $12.240,00$ & Prejuízo & $-\mathrm{R} \$$ & $625.000,00$ \\
\hline TOTAL DO ATIVO & $\mathbf{R} \mathbf{S}$ & $151.020,00$ & TOTAL DO PASSIVO & $\mathbf{R} \mathbf{S}$ & $151.020,00$ \\
\hline
\end{tabular}

Tabela 2: Balanço Patrimonial da filial da empresa aberta no shopping.

Fonte: Adaptado Dados da Pesquisa (2019).

O casal começou a fazer inferências sobre os primeiros resultados, e ligou para Pedro:

- Oi, Pedro, é a Maria. Bom dia!

- Olá, D. Maria! Tudo bem? Recebeu os documentos? - perguntou ele. 
- Recebi sim e estou assustada! É tudo isso de prejuízo mesmo?

- D. Maria, sinto muito, esta é a situação da sua filial, é o que os números dizem - falou Pedro - a Senhoraviu a folha com os índices do negócio e a análise do investimento?

- Espera aí... Meu Deus! - exclamou Maria.

Pedro tentou tranquilizá-la:

- D. Maria, sinto muito! Trabalho há anos para vocês e sei da capacidade empreendedora de vocês! Outros clientes também estão nessa situação.

Maria começou a observar os índices do negócio (Tabela 3).

\begin{tabular}{|c|c|c|}
\hline \multicolumn{3}{|c|}{ ÍNDICES DE LIQUIDEZ } \\
\hline LIQUIDEZ CORRENTE & $(-\mathrm{R} \$ 48.500,00 / \mathrm{R} \$ 185.844,00)$ & $-0,26$ \\
\hline LIQUIDEZ SECA & $(-\mathrm{R} \$ 49.730,00 / \mathrm{R} \$ 185.844,00)$ & $-0,27$ \\
\hline LIQUIDEZ IMEDIATA & $(-\mathrm{R} \$ 49.730,00 / \mathrm{R} \$ 185.844,00)$ & $-0,27$ \\
\hline LIQUIDEZ GERAL & $(\mathrm{R} \$ 151.020,00 / \mathrm{R} \$ 556.020,00)$ & 0,27 \\
\hline \multicolumn{3}{|c|}{ ÍNDICES DE ENDIVIDAMENTO } \\
\hline PART CAP TERCEIROS & {$[(\mathrm{R} \$ 185.844,00+\mathrm{R} \$ 370.176,00) / \mathrm{R} \$ 151.020,00]$} & 3,68 \\
\hline $\begin{array}{l}\text { COMP. DO ENDIVIDA- } \\
\text { MENTO }\end{array}$ & {$[\mathrm{R} \$ 185.844,00 /(\mathrm{R} \$ 185.844,00+370.176,00)]$} & 0,33 \\
\hline IMOBILIZAÇÃO DO PL & $(\mathrm{R} \$ 199.520,00 / \mathrm{R} \$ 220.000,00)$ & 0,91 \\
\hline \multicolumn{3}{|c|}{ ÍNDICES DE RENTABILIDADE } \\
\hline RETORNO INVESTIMENTO & {$[(-\mathrm{R} \$ 625.000,00-\mathrm{R} \$ 577.800,00) / \mathrm{R} \$ 577.800,00] * 100$} & $-208,17$ \\
\hline RETORNO PATRIMÔNIO & $(-\mathrm{R} \$ 625.000,00 /-\mathrm{R} \$ 405.000,00)$ & 1,54 \\
\hline
\end{tabular}

Tabela 3: Cálculo dos índices do negócio.

Fonte: Adaptado Dados da Pesquisa (2019).

Em seguida, observou os indicadores da análise do investimento (Tabela 4).

\begin{tabular}{lcc}
\multicolumn{1}{c}{ ANO } & INICIAL (07/2017) & FINAL (03/2018) \\
\hline FLUXO DE CAIXA FINAL & $-\mathrm{R} \$ 577.800,00$ & $\mathrm{R} \$ 37.800,00$ \\
FLUXO DE CAIXA ACUMULADO & $-\mathrm{R} \$ 577.800,00$ & $-\mathrm{R} \$ 540.000,00$ \\
FLUXO DE CAIXA DESCONTADO & $-\mathrm{R} \$ 577.800,00$ & $\mathrm{R} \$ 30.483,87$ \\
FLUXO DE CAIXA DESCONTADO E ACUMULADO & $-\mathrm{R} \$ 577.800,00$ & $-\mathrm{R} \$ 547.316,13$ \\
VALOR PRESENTE LÍQUIDO (VPL) & $-\mathrm{R} \$ 539.999,76$ & - \\
TAXA INTERNA DE RETORNO (TIR) & $-93,46 \%$ & - \\
PAYBACK SIMPLES & 15,28 anos & - \\
PAYBACK DESCONTADO & Acima do limite fixado de 20 anos & - \\
\hline
\end{tabular}

Tabela 4: Indicadores de análise do investimento.

Fonte: Adaptado Dados da Pesquisa (2019).

Logo após, Maria respondeu:

- Eu sei, Pedro. Muitos comerciantes com os quais temos contato estão se virando como podem, mas acho que nossa situação é crítica. Grande parte dos nossos índices estão negativos! Além disso, a análise do investimento não é nada otimista! - disse ela.

- D. Maria, infelizmente, a situação não é nada fácil, mas gostaria que a senhora olhasse os documentos com calma, e, qualquer coisa, estou aqui para esclarecer as dúvidas... - Pedro falou, tentando, mais uma vez, acalmá-la.

- Obrigada, Pedro! Gostaria de agradecer sua atenção e vou decidir com João o que faremos. - Maria encerrou a conversa.

Mais tarde, Maria voltou a falar com João:

- João, nossa situação é crítica, daqui a pouco perderemos tudo se continuarmos com este negócio!

- Mas, Maria, até engrenar, teremos prejuízo... precisamos ter calma neste momento - disse ele.

Nesse momento, pairavam no ar muitas dúvidas. Até então uma trajetória de sucesso tinha sido projetada. A princípio, Maria tinha obtido sucesso nos seus planos. Contudo, entre uma decisão e outra, 
a empresa parecia correr ladeira abaixo. 0 casal sabia que precisava tomar algumas decisões para alavancar a empresa. Maria e João precisavam agir rápido, diante do dilema: Fechar ou revitalizar o jardim? Permanecer com o projeto de expansão da loja, assumindo novos riscos, ou fechá-la, retomando exclusivamente as atividades na matriz? 


\section{Notas de ensino}

O caso para ensino compreende um importante instrumento pedagógico, pois sua aplicabilidade alia os conceitos teóricos à prática, trazendo dinamicidade para a aula e tornando o processo de ensinoaprendizagem mais eficiente e efetivo (Roesch, 2007). 0 caso explanado, ao relatar a trajetória do casal Silva, demonstrando a tomada de decisão sem informações importantes à expansão do negócio de forma sustentável, oferece um conteúdo relevante para o ensino de gestão, estratégia, empreendedorismo e análise financeira.

As notas de ensino compreendem sugestões e direcionamentos para auxiliar os professores na aplicação do caso, orientando-os quanto: aos objetivos de ensino; às fontes de dados e aos métodos da sua produção; aos cursos e às disciplinas sugeridas para o uso do caso; à fundamentação teórica; às questões norteadoras para discussão do caso; à organização e ao planejamento da aula; e às sugestões de bibliografia para dar subsídio ao conteúdo trabalhado.

\subsection{Objetivo de ensino}

Espera-se que os alunos: a) desenvolvam a capacidade de analisar a importância das informações, internas e externas à empresa, para a tomada de decisões; b) compreendam o papel do diagnóstico da empresa, auxiliado por instrumentos como o Plano de Negócios, Business Model Canvas, Matriz SWOT etc.; c) desenvolvam competências para avaliar situações complexas, diagnosticando problemas e desenvolvendo alternativas para solucioná-los; e d) compreendam a relevância de discutir ações estratégicas para desenvolver o negócio de maneira sustentável, considerando o papel dos indicadores financeiros para a saúde do negócio.

\subsection{Fontes de dados e métodos}

As informações que fundamentam este caso para ensino foram produzidas por meio de uma entrevista semiestruturada com o casal de empreendedores. Foi realizada uma visita in loco ao empreendimento e, na ocasião, além da escuta ativa, observou-se as rotinas organizacionais. A entrevista foi gravada, com o consentimento dos empreendedores, para a obtenção das informações completas e fidedignas, evitando a incompletude ou a distorção das informações. Ademais, como fontes de dados secundárias, coletaram-se informações de materiais divulgados pela imprensa, pelas mídias sociais e pelos jornais. Trata-se de uma história real, contudo os diálogos foram simulados de modo a ilustrar a sequência dos fatos.

\subsection{Cursos/disciplinas sugeridas para uso do caso}

O conteúdo e as abordagens deste caso são sugeridos para cursos de graduação e pós-graduação em Administração, Gestão de Negócios, Gestão Empresarial e áreas afins, no tocante às disciplinas de Empreendedorismo, Gestão de Negócios, Planejamento Estratégico e Análise Financeira.

\subsection{Fundamentação teórica}

No período que antecedeu a crise econômica atual, o cenário do Nordeste era caracterizado pelo aumento de sua base produtiva e pela atração de investimentos em setores como o comércio, representado pelo movimento de interiorização de shoppings e supermercados (Felipe, 2018), fato que proporcionou a inserção de micro e pequenos negócios nesses grandes empreendimentos. Porém, percebeuse uma alta taxa de mortalidade desses pequenos negócios, dificultando a permanência das grandes estruturas - os shoppings centers, fato que pode ser justificado por razões como: a estagnação da economia, a alta concorrência, as taxas exorbitantes de condomínio para alocação nesses empreendimentos, o despreparo dos lojistas quanto ao planejamento e à gestão do negócio (Neves \& Pessoa, 2006; SEBRAE, 2014).

Considerar a decisão de continuar com a loja no shopping envolve diferentes riscos, como a necessidade de maiores investimentos para manter as despesas ou a criação de um plano para atrair novos clientes. Do mesmo modo, fechar a loja e se dedicar, de forma exclusiva, à matriz requer ações para estabilizar o negócio. Pensar estrategicamente em novas direções, diante do dilema que o casal de empreendedores se encontra, demanda conhecimentos gerenciais e suporte de ferramentas que auxiliem à tomada de decisão, que segundo Campos (2015), são fundamentais em todas as etapas evolutivas do empreendimento.

O caso apresentado propõe abordagens acerca da gestão de negócios, trazendo proposições que 
revelam a importância do planejamento estratégico, auxiliado pelas ferramentas gerenciais, bem como aborda fundamentos sobre empreendedorismo com ênfase no perfil empreendedor. Segundo o SEBRAE (2013, p. 12), empreendedor é aquele que "[...] persiste, acredita em sua capacidade e vê os fracassos como oportunidades de aprendizado. Planeja e avalia os resultados alcançados, buscando excelência naquilo que desenvolve". Assumem, portanto, características como persistência, detecção de oportunidades, inovação, planejamento, disposição para assumir riscos etc. (Schmidt \& Bohnenberger, 2009), semelhantes às características do casal Silva.

No momento em que o casal de empreendedores expandiu seus negócios, aceitando a proposta do Sr. Linhares, abrindo uma filial no shopping e não obtendo sucesso, emergiram fatores que podem ser discutidos na análise do caso. Mintzberg, Lampel, Quinn, \& Ghoshal (2006) afirmam que o processo estratégico, embora planejado e executado com afinco, não garante a paridade com a realidade devido à imprevisibilidade do ambiente de negócios, estabelecendo limites à capacidade de análise estratégica. Isso reflete três estratégias: a estratégia pretendida resultado de decisões embasadas em análises ambientais prévias, contudo parte dela nem sempre é implementada devido às mudanças que ocorrem no ambiente; isso gera a estratégia emergente, fruto de novas decisões no meio do caminho; e por fim, a estratégia realizada produto das decisões decorrentes das duas estratégias anteriores.

A construção de estratégias bem-sucedidas pode ser ancorada em ferramentas como o Plano de Negócios, Modelo de Negócios, Matriz SWOT - acrônimo de Strenghts (Forças), Weaknesses (Fraquezas), Opportunities (Oportunidades) e Threats (Ameaças) - etc. O Plano de Negócios é essencial para qualquer empreendedor, pois fornece uma descrição minuciosa acerca do planejamento do negócio ao detalhar as oportunidades identificadas. Esse plano é composto pelo sumário executivo, plano de gestão, plano de marketing, plano tecnológico e plano financeiro (Dornelas, 2012), resultando em um documento formal contendo a visão do empreendedor sobre o negócio, sua viabilidade e rentabilidade (Baron, 2011).

Para o SEBRAE (n.d., p. 13), “[...] o Modelo de Negócio precede a elaboração do plano de negócios [...] [o qual] descreve a lógica de criação do negócio, quer dizer, mostra que o raciocínio e a interconexão das partes fazem sentido". Ou seja, além de apoiar o desenvolvimento e documentação de modelos de negócio (Campos, 2015), representa uma linguagem comum capaz de auxiliar a implementação de projetos empreendedores, o que poderia contribuir, no caso apresentado, para os empreendedores modelarem o negócio a ser expandido. A ferramenta é composta por nove componentes - Segmentos de clientes, Proposta de valor, Canais, Relacionamento com os clientes, Fontes de receita, Recursos principais, Atividades chave, Parcerias principais, e Estrutura de custo - distribuídos entre quatro áreas: clientes, oferta, infraestrutura e viabilidade financeira (Ostewalder \& Pigneur, 2011).

Outra ferramenta utilizada pelos empreendedores é a Matriz SWOT, que consiste em um instrumento de autoavaliação empresarial que ajuda a identificar os pontos fortes e fracos da organização (fatores internos) e as variáveis externas como oportunidades, que se aproveitadas geram um retorno positivo para o negócio, e as ameaças, que podem prejudicar as ações da empresa, como aspectos políticos, econômicos, culturais etc. (Andrade, 2012).

Como visto no caso, a interpretação das informações e a caracterização das condições econômicofinanceiras da empresa são substanciais para a tomada de decisão (Fernandes, Peguinho, Vieira, \& Neiva, 2016). A partir das demonstrações financeiras, elaboradas pelo contador Pedro, é possível realizar uma análise da empresa, subsidiando tomadas de decisões mais assertivas (Lima \& Lima, 2013). Para Lima e Lima (2013, p. 05), o Balanço Patrimonial e a Demonstração do Resultado do Exercício (DRE) são as demonstrações financeiras mais evidenciadas, visto que apresentam "[...] de forma objetiva a situação financeira e econômica da entidade respectivamente".

Ainda sobre indicadores importantes para análise da viabilidade do negócio, tem-se a taxa de Atratividade que, neste caso, deve ser maior do que a média de retorno da empresa matriz (Gallon, Silva, Hein \& Olinquevitch, 2006). Ao considerar os fluxos de caixa (acumulado e/ou descontado), se o Valor Presente Líquido (VPL) for negativo, indica um retorno inferior à Taxa Mínima de Atratividade (TMA), além da Taxa Interna de Retorno (TIR) que também é aplicada com base no fluxo de caixa; e se é menor que a TMA, contribui para a inviabilidade da empresa, uma vez que seu retorno é superado pelo retorno de um investimento sem risco (Assaf Neto, 1992; Gallon et al., 2006). Ademais, outro índice a ser analisado é o Payback (simples e descontado), que visa a demonstrar o número de períodos (anos) necessários para que o fluxo de benefícios supere o capital investido (Gallon et al., 2006).

Dentre outros aspectos, entende-se que o casal Silva deveria ter realizado uma pesquisa de mercado, objetivando a compreensão do cenário relacionado ao desempenho dos shoppings no Nordeste, 
ao índice de fechamento de lojas, ao tempo de retorno sobre o investimento, aos custos de manutenção de uma loja em shopping, além de outros fatores relacionados aos dados financeiros e ao próprio planejamento estratégico e diagnóstico ambiental. Caberia, inclusive, uma pesquisa de mercado acerca da aceitação do produto (pastel) e sensibilidade ao preço, que seria mais alto na filial do shopping.

Isso demonstra a relevância de os empreendedores adquirirem conhecimentos para gerenciar seus negócios, transformando-os em organizações rentáveis com perspectiva de crescimento baseada em atividades direta ou indiretamente ligadas ao planejamento do negócio (Chiavenato, 2012).

\subsection{Questões norteadoras para a discussão do caso}

Com vistas a explorar o caso para ensino, sugerem-se algumas questões norteadoras para discussão em sala de aula, além daquelas expostas no desfecho do caso:

1) A decisão tomada por João, de fechar o contrato, foi acertada? Discuta sobre os elementos determinantes do desfecho do caso.

2) Como você conduziria as decisões se estivesse na situação do casal Silva? Justifique (sugerem-se trabalhar com ferramentas para subsidiar as decisões).

3) Quais as principais características do perfil empreendedor do casal Silva que contribuíram para o sucesso inicial do negócio? Quais as características, ou a falta delas, conduziram aos percalços gerados na trajetória? Discuta.

4) Como o Plano de Negócios poderia auxiliar o casal Silva na tomada de decisão sobre a expansão do negócio? Discuta sobre as contribuições das ferramentas de Gestão de Negócios e Planejamento Estratégico (Business Model Canvas, SWOT etc.).

5) Por que o conhecimento e compreensão dos indicadores financeiros apresentados pelo contador seriam úteis para o casal Silva? E com relação à análise do investimento? Justifique, discutindo acerca da importância da análise financeira para os negócios.

\subsection{Organização e planejamento da aula para uso do caso}

Inicialmente, uma informação essencial para a condução dessa atividade em sala de aula é a ciência da decisão tomada pelo casal de empreendedores no desfecho da história, possibilitando, no decorrer das análises e discussões, a exploração de novos caminhos. A decisão foi de fechar a loja do shopping e de redirecionar seus esforços para a loja matriz, subsidiada pela análise feita de todo o material enviado pelo contador Pedro. No material, foi possível identificar, entre outros dados: o VPL negativo (no valor de -R \$ 539.999,76) e a TIR igual a $-93,46 \%$ que indicam um retorno inferior à TMA, revelando-se economicamente desinteressante; e o Payback simples (acima de 15 anos) e o Payback descontado (acima de 20 anos - limite fixado), que confirmaram a inviabilidade da manutenção do negócio.

A exequibilidade do estudo do caso em sala de aula pode ser feita em grupos e o professor solicitará a divisão da turma em equipes com cinco integrantes - quantidade ajustada conforme o número de alunos. Sugerem-se um planejamento para aulas de duas horas (Quadro 1) ajustado, conforme o tempo disponível.

\begin{tabular}{|c|l|c|}
\hline Passo a passo & \multicolumn{1}{|c|}{ Descrição das atividades } & $\begin{array}{c}\text { Tempo } \\
\text { estimado }\end{array}$ \\
\hline Passo 1 & $\begin{array}{l}\text { Apresentação do caso e dos objetivos de ensino, bem como explicação da atividade } \\
\text { pelo professor. }\end{array}$ & 15 minutos \\
\hline Passo 2 & $\begin{array}{l}\text { 1) Divisão dos grupos. A divisão dos grupos pode ser coordenada pelo professor, de } \\
\text { forma aleatória ou por meio de uma dinâmica, como a dinâmica das cores ou dos } \\
\text { animais, na qual o professor distribui entre os alunos papeletas, identificando uma } \\
\text { cor ou um animal e, ao comando do professor, cada aluno buscará entre os colegas } \\
\text { seus semelhantes para formar o grupo; 2) Leitura, discussão e análise do caso pelos } \\
\text { alunos. Os discentes poderão elaborar mapas conceituais, preenchimento de planos } \\
\text { de negócios, análise SWOT ou uso de outros recursos, orientados pelo professor, para } \\
\text { subsidiar as soluções propostas e posterior discussão das questões apresentadas no } \\
\text { caso para ensino. }\end{array}$ & 30 minutos \\
\hline Passo 3 & $\begin{array}{l}\text { Discussão das ideias gerais do caso (turma inteira), levantamento de dúvidas e } \\
\text { alinhamento dos conhecimentos adquiridos por meio da leitura e discussão em grupo. } \\
\text { Essa discussão será norteada pelos questionamentos propostos no desfecho do caso, } \\
\text { refletindo sobre: Quais são os impactos dessas decisões? Quais estratégias podem ser } \\
\text { desenvolvidas para reerguer o negócio, caso a decisão seja por esse caminho? E se a }\end{array}$ & 20 minutos \\
\hline
\end{tabular}




\begin{tabular}{|c|l|c|}
\hline & $\begin{array}{l}\text { decisão for por fechar a loja? Quais ferramentas estratégicas poderiam ser úteis nessa } \\
\text { tomada de decisão? }\end{array}$ \\
\hline Passo 4 & $\begin{array}{l}\text { Análise e discussão das questões norteadoras para discussão do caso (seção 3.5). 0 } \\
\text { debate aberto surge por meio da exposição das soluções propostas por cada grupo, } \\
\text { tendo o professor como mediador das discussões e dos direcionamentos das } \\
\text { alternativas mais efetivas que conduzam a compreensão do conteúdo o oprendizado } \\
\text { dos alunos. Para a realização de um debate organizado e coordenado, é recomendado } \\
\text { que o docente, logo no início da aula, deixe as "regras do jogo" transparentes e faça } \\
\text { isso de forma que a turma tenha entendido e concordado com elas. }\end{array}$ & 40 minutos \\
\hline Passo 5 & $\begin{array}{l}\text { Como etapa final da aula, sugere-se a realização de feedbacks do docente para os } \\
\text { discentes de modo a realizar o fechamento adequado do processo de ensino- } \\
\text { aprendizagem. Deve-se retomar às anotações feitas, ressaltando os pontos positivos } \\
\text { que foram destacados nas análises realizadas pelos alunos, fortalecendo os } \\
\text { ensinamentos gerados com o estudo do caso e indicando pontos de melhorias } \\
\text { observados. Dessa forma, o sistema de ensino da disciplina será retroalimentado e } \\
\text { gerará aprendizado. Ressalta-se a importância de estimular os estudantes a fazerem } \\
\text { suas avaliações e pontuarem fatores que foram interessantes nesse processo, bem } \\
\text { como fatores que não atenderam às expectativas de ensino com qualidade. }\end{array}$ & 15 minutos \\
\hline $\begin{array}{l}\text { Observação: Para otimizar o tempo da análise durante a aula, o professor pode solicitar aos alunos a leitura prévia do caso } \\
\text { e anotaçóes sobre os principais pontos. Considerando que a discussão em sala de aula será mais proveitosa, visto que partirá } \\
\text { do princípio de que todos leram com calma e fizeram suas anotações, é possível iniciar a aula lançando um questionamento } \\
\text { para discussão em grupo. O docente estipulará o tempo necessário para a discussão, como sugerido anteriormente. A ideia, } \\
\text { aqui, é trabalhar com um tempo mais curto, considerando que o caso já tenha sido lido antecipadamente. }\end{array}$ \\
\hline
\end{tabular}

Quadro 1: Planejamento de aula para estudo do caso.

Fonte: Elaborado pelos autores (2020).

Como plano de aula alternativo, sugerem-se outros questionamentos para nortear a compreensão e discussão do caso (Quadro 2). Cada grupo ficará responsável por apresentar uma fase da história, realizando observações, propondo caminhos alternativos ou decisões diante das situações. Os questionamentos deverão ser discutidos em grupo e explanados para a turma. Nessas discussões, novas alternativas poderão emergir, contribuindo para o aprendizado coletivo. 0 plano é sugerido para aulas de duas horas (ajustado conforme o tempo disponível), nas quais o docente conduzirá e mediará as apresentações e discussões.

\begin{tabular}{|c|c|c|}
\hline Responsável & Seção/Tempo estimado & Decisões e dilemas \\
\hline Professor & $\begin{array}{l}\text { Abertura da aula } \\
10 \text { minutos }\end{array}$ & $\begin{array}{l}\text { Apresentação do caso e dos objetivos de ensino, bem como explicação da } \\
\text { atividade pelo professor. }\end{array}$ \\
\hline Grupo 1 & $\begin{array}{l}\text { Eva e Adão no Jardim do } \\
\text { Éden: o princípio } \\
20 \text { minutos }\end{array}$ & $\begin{array}{l}\text { 1. Quais elementos podem ser identificados no início da história para o } \\
\text { sucesso do negócio? (exemplo: perfil empreendedor, superação ao } \\
\text { contexto de dificuldades econômicas, networking, visão de futuro etc.). } \\
\text { Discuta. } \\
\text { 2. O que justifica o sucesso da empresa e o seu reconhecimento no âmbito } \\
\text { local e nacional? } \\
\text { 3. Quais as características empreendedoras que influenciaram no sucesso } \\
\text { do negócio? Justifique. }\end{array}$ \\
\hline Grupo 2 & $\begin{array}{l}\text { Eva e a serpente: a proposta } \\
\qquad 20 \text { minutos }\end{array}$ & $\begin{array}{l}\text { 1. Quais são as características empreendedoras de Maria que justificam a } \\
\text { sua rejeição à proposta? } \\
\text { 2. Qual a importância de conhecer os fatores ambientais (economia, } \\
\text { cultura, comportamento social etc.) para a expansão e sucesso dos } \\
\text { negócios? }\end{array}$ \\
\hline Grupo 3 & $\begin{array}{l}\text { O fruto proibido é comido: a } \\
\text { aceitação } \\
20 \text { minutos }\end{array}$ & $\begin{array}{l}\text { 1. Como você avalia a decisão de João e suas características } \\
\text { empreendedoras? } \\
\text { 2. Por que Maria sugeriu a realização de um plano de negócios e estudo de } \\
\text { viabilidade? Discuta acerca da importância desse material para a Gestão de } \\
\text { Negócios e a relevância de um Planejamento Estratégico. }\end{array}$ \\
\hline Grupo 4 & $\begin{array}{l}\text { O Conhecimento do bem e do } \\
\text { mal: as consequências } \\
20 \text { minutos }\end{array}$ & $\begin{array}{l}\text { 1. Como você avalia a gestão dos negócios no tocante à retirada de recursos } \\
\text { financeiros da matriz para investir na filial? } \\
\text { 2. Como você avalia a importância da Educação Empreendedora e dos } \\
\text { conhecimentos de análise financeira naquela situação? } \\
\text { 3. Discuta sobre os riscos de envolver recursos pessoais (nessa situação, o } \\
\text { investimento por meio da venda da casa do casal) nos negócios. }\end{array}$ \\
\hline Grupo 5 & $\begin{array}{l}\text { Fechar ou revitalizar o } \\
\text { jardim: será o fim? }\end{array}$ & $\begin{array}{l}\text { 1. Quais foram as estratégias utilizadas por Maria para tentar contornar a } \\
\text { situação? O que você sugeriria? }\end{array}$ \\
\hline
\end{tabular}




\begin{tabular}{|c|c|c|}
\hline & 20 minutos & $\begin{array}{l}\text { 2. Qual a importância do conhecimento dos indicadores financeiros para a } \\
\text { saúde e sucesso do negócio? Justifique. } \\
\text { 3. Como você avalia a relação entre a análise financeira e a tomada de } \\
\text { decisões estratégicas? } \\
\text { 4. Como você avalia a decisão tomada pelo casal de empreendedores no } \\
\text { desfecho do caso? Justifique. }\end{array}$ \\
\hline $\begin{array}{c}\text { Professor e } \\
\text { alunos }\end{array}$ & $\begin{array}{l}\text { Fechamento da aula } \\
10 \text { minutos }\end{array}$ & $\begin{array}{l}\text { Como etapa final da aula, sugere-se a realização de feedbacks do docente } \\
\text { para os discentes de modo a realizar o fechamento adequado do processo } \\
\text { de ensino-aprendizagem. Deve-se retomar às anotações feitas, ressaltando } \\
\text { os pontos positivos que foram destacados nas análises realizadas pelos } \\
\text { alunos, fortalecendo os ensinamentos gerados com o estudo do caso e } \\
\text { indicando pontos de melhorias observados. Dessa forma, o sistema de } \\
\text { ensino da disciplina será retroalimentado e gerará aprendizado. Ressalta- } \\
\text { se a importância de estimular os estudantes a fazerem suas avaliações e } \\
\text { pontuarem fatores que foram interessantes nesse processo, bem como } \\
\text { fatores que não atenderam às expectativas de ensino com qualidade. }\end{array}$ \\
\hline
\end{tabular}

Quadro 2: Planejamento alternativo para estudo do caso.

Fonte: Elaborado pelos autores (2020).

Por fim, é possível solicitar a elaboração de um mapa conceitual do caso proposto e a análise realizada pelos alunos como parte integrante da avaliação da disciplina. Além disso, o professor pode considerar o envolvimento dos alunos nas apresentações e discussões como parte do processo avaliativo.

\subsection{Sugestões de bibliografia}

Para orientar professores e alunos acerca dos aspectos teóricos, sugere-se a bibliografia para estudo complementar presentes no Quadro 3.

\begin{tabular}{|c|c|}
\hline Títulos & Disciplinas \\
\hline Antonik, L. R \& Muller, A. N. (2017). Avaliação de empresas para leigos. Alta Books Editora. & Análise Financeira \\
\hline $\begin{array}{l}\text { Dess, G. G., Lumpkin, G. T., Eisner, A. B., \& Mcnamara, G. (2016). Administração estratégica: a } \\
\text { criação de vantagens competitivas. Rio de Janeiro: Alta Books. }\end{array}$ & Planejamento Estratégico \\
\hline $\begin{array}{l}\text { Dornelas, J. C. A. (2012). Empreendedorismo. Transformando ideias em Negócios. 4a ed. Rio de } \\
\text { Janeiro: Elsevier. }\end{array}$ & $\begin{array}{l}\text { Empreendedorismo } \\
\text { Gestão de Negócios }\end{array}$ \\
\hline $\begin{array}{l}\text { Fernandes, C., Peguinho, C., Vieira, E., \& Neiva, J. (2016). Análise Financeira: Teoria e Prática. 4a } \\
\text { ed. Lisboa: Edições Sílabo. }\end{array}$ & Análise Financeira \\
\hline $\begin{array}{l}\text { Flávio K. (2019). Análise de demonstrativos financeiros e da performance empresarial: para em- } \\
\text { presas não financeiras. Saint Paul. }\end{array}$ & Análise Financeira \\
\hline $\begin{array}{l}\text { Grossi, R., \& Oliveira, J. B. (2009). As particularidades das pequenas empresas sob a ótica do } \\
\text { empreendedorismo e da teoria do processo de formação das estratégias. In: Encontro Nacional } \\
\text { da ANPAD, XXXIII, 2009, São Paulo. Anais [...]. São Paulo: EnANPAD. }\end{array}$ & $\begin{array}{l}\text { Empreendedorismo } \\
\text { Gestão de Negócios } \\
\text { Planejamento Estratégico }\end{array}$ \\
\hline $\begin{array}{l}\text { Lima, A. F. A., \& Lima, J. E. C. (2013). Índices econômico-financeiros como instrumentos para } \\
\text { análise das demonstrações financeiras na tomada de decisão gerencial. Revista Interfaces: Sa- } \\
\text { úde, Humanas e Tecnologia, Juazeiro do Norte, } 1(3), 01-16 .\end{array}$ & $\begin{array}{c}\text { Análise Financeira } \\
\text { Planejamento Estratégico }\end{array}$ \\
\hline $\begin{array}{l}\text { Lopes, R. M. A (Org.). (2010). Educação Empreendedora: conceitos, modelos e práticas. Rio de } \\
\text { Janeiro: Elsevier; São Paulo: SEBRAE. }\end{array}$ & Empreendedorismo \\
\hline Ludicibus. S. (2017). Análise de Balanços. 11a ed. São Paulo: Atlas. & Análise Financeira \\
\hline $\begin{array}{l}\text { Mintzberg, H., Lampel, J., Quinn, J. B., \& Ghoshal, S. (2006). O Processo da Estratégia: Conceitos, } \\
\text { Contextos e Casos Selecionados. 4a ed. Porto Alegre: Bookman. }\end{array}$ & $\begin{array}{l}\text { Planejamento Estratégico } \\
\text { Gestão de Negócios }\end{array}$ \\
\hline $\begin{array}{l}\text { Oliveira, D. P. R. (2018). Planejamento Estratégico: conceitos, metodologias, práticas. 34a ed. } \\
\text { São Paulo: Atlas. }\end{array}$ & Planejamento Estratégico \\
\hline Rosa, C. A. (2007). Como elaborar um plano de negócio. Brasília: SEBRAE. & Gestão de Negócios \\
\hline $\begin{array}{l}\text { Schmidt, S. \& Bohnenberger, M. C. (2009) Perfil Empreendedor e Desempenho Organizacional. } \\
\text { Revista de Administração Contemporânea, Maringá, 13(3), 450-467. }\end{array}$ & $\begin{array}{l}\text { Empreendedorismo } \\
\text { Gestão de Negócios }\end{array}$ \\
\hline $\begin{array}{l}\text { Serviço Brasileiro de Apoio às Micro e Pequenas Empresas - SEBRAE. (2013). Manual do aluno } \\
\text { disciplina de Empreendedorismo. Módulo } 1 \text { - O Empreendedor. Brasília: SEBRAE. }\end{array}$ & Empreendedorismo \\
\hline $\begin{array}{l}\text { Serviço Brasileiro de Apoio às Micro e Pequenas Empresas - SEBRAE. (n.d.). Cartilha. O quadro } \\
\text { de modelo de negócios: um caminho para criar, recriar e inovar em modelos de negócios. Recu- } \\
\text { perado em } 11 \text { julho, 2019, de https://bibliotecas.sebrae.com.br/chronus/ARQUIVOS_CHRO- } \\
\text { NUS/bds/bds.nsf/be606c09f2e9502c51b09634badd2821/\$File/4439.pdf. }\end{array}$ & $\begin{array}{l}\text { Gestão de Negócios } \\
\text { Empreendedorismo }\end{array}$ \\
\hline Silva. J. P. (2006). Análises Financeiras das Empresas. 8a ed. São Paulo: Atlas. & Análise Financeira \\
\hline $\begin{array}{l}\text { Verga, E., \& Silva, L. F. S. (2014). Empreendedorismo: evolução histórica, definições e aborda- } \\
\text { gens. Revista de Empreendedorismo e Gestão de Pequenas Empresas, São Paulo, 3(3), 03-30. }\end{array}$ & Em \\
\hline
\end{tabular}

Quadro 3: Bibliografias sugeridas para estudo.

Fonte: Elaborado pelos autores (2020). 


\section{Nota}

O presente trabalho foi realizado com apoio da Coordenação de Aperfeiçoamento de Pessoal de Nível Superior - Brasil (CAPES) - Código de Financiamento 001.

\section{Referências}

Andrade, A. R. (2012). Planejamento estratégico: formulação, implementação e controle. São Paulo: Atlas. Assaf Neto, A. (1992). Os métodos quantitativos de análise de investimentos. Caderno de Estudos, (6), 116.

Baron, R. A. (2011). Empreendedorismo: uma visão do processo. São Paulo: Cengage Learning.

Campos, N. M. (2015). The myth of the idea: and the upsidedown startup. Charleston: Createspace.

Chiavenato, I. (2012). Empreendedorismo: dando asas ao espírito empreendedor. 4a ed. São Paulo: Manole.

Dornelas, J. C. A. (2012). Empreendedorismo. Transformando ideias em Negócios. 4a ed. Rio de Janeiro: Elsevier.

Felipe, J. L. A. (2018). Dinâmicas socioeconômicas do nordeste brasileiro. Revista da Casa da Geografia de Sobral, 20(1), 80-90.

Fernandes, C., Peguinho, C., Vieira, E., \& Neiva, J. (2016). Análise Financeira: Teoria e Prática. 4a ed. Lisboa: Edições Sílabo.

Gallon, A. V., Silva, T. P., Hein, N., \& Olinquevitch, J. L. (2006). Utilização da análise de investimento nas empresas de tecnologia do vale do Itajaí/SC. In: Simpósio de Gestão da Inovação Tecnológica, XXIV, Gramado. Anais [...]. Gramado: GCT/ANPAD.

Lima, A. F. A., \& Lima, J. E. C. (2013). Índices econômico-financeiros como instrumentos para análise das demonstrações financeiras na tomada de decisão gerencial. Revista Interfaces: Saúde, Humanas e Tecnologia, 1(3).

Mintzberg, H., Lampel, J., Quinn, J. B., \& Ghoshal, S. (2006). O Processo da Estratégia: Conceitos, Contextos e Casos Selecionados. 4a ed. Porto Alegre: Bookman.

Neves, J. A. D. \& Pessoa, R. W. A. (2006). Causas da mortalidade de micros e pequenas empresas: o caso das lojas de um shopping center. Revista Organizações em contexto, 2(4), 165-195.

Osterwalder, A., \& Pigneur, Y. (2011). Business Model Canvas - Inovação em Modelos de Negócios. Um Manual para Visionários, Inovadores e Revolucionários. Rio de Janeiro: Alta Books.

Roesch, S. M. A. (2007). Como escrever casos para o ensino de Administração. São Paulo: Atlas.

Schmidt, S., \& Bohnenberger, M. C. (2009). Perfil Empreendedor e Desempenho Organizacional. RAC, Curitiba, 13(3).

SEBRAE. (2013). Manual do aluno disciplina de Empreendedorismo. Módulo 1 - 0 Empreendedor. Brasília: SEBRAE.

SEBRAE. (2014) Causa mortis: O sucesso e o fracasso das empresas nos primeiros 5 anos de vida. Recuperado em 28 outubro, 2020, de https://www.sebrae.com.br/Sebrae/Portal\%20Sebrae/UFs/SP/Pesquisas/CAUSA\%20MORTIS_vf.pdf.

SEBRAE. (2017). Pastelaria de Aracaju inova e se torna referência para moradores e turistas. Pequenas Empresas \& Grandes Negócios. Recuperado em 11 julho, 2019, de https://revistapegn.globo.com/Negocios/noticia/2017/10/pastelaria-de-aracaju-inova-e-se-torna-referencia-para-moradores-e-turistas.html.

SEBRAE. (n.d.). Cartilha. O quadro de modelo de negócios: um caminho para criar, recriar e inovar em modelos de negócios. Recuperado em 11 julho, 2019, de https://bibliotecas.sebrae.com.br/chronus/ARQUIVOS_CHRONUS/bds/bds.nsf/be606c0 9f2e9502c51b09634badd2821/\$File/4439.pdf. 